\title{
Recovery of latent fingermarks from burial environments
}

\author{
Yam Tze Yong ${ }^{1,2}$, Yusmazura Zakaria ${ }^{3}$ and Nik Fakhuruddin Nik Hassan ${ }^{2^{*}}$ (D)
}

\begin{abstract}
Background: Fingermarks can be found both in indoor and outdoor crime scenes. The latter could be subjected to various types of environmental insults. In many cases, criminals try to dispose of or conceal the evidence in several ways, such as throwing in the waterways or burying in the soil to avoid detection from the law enforcement agencies. Thus, crime scene investigators often face challenges to detect and develop latent fingermarks in such environments. This study aimed to investigate the persistence and ageing of latent fingermarks in a burial environment for particular periods. To date, there is a limited study that attempted to investigate the survivability of fingermarks in a burial environment.

Methodology: The experiment was carried out in two settings: preliminary and main experiments. A preliminary experiment was conducted indoor to determine the most effective chemical for fingermark development on buried metal substrates. Five different chemicals were employed to develop the latent fingermarks, namely fingermark powder dusting, small particle reagent (SPR), Sudan black, oil red O, and crystal violet. The main experiment was carried out to simulate the realistic situation in which the metal substrates bearing latent fingermarks were buried in the soil within 2 months period. In both experiments, the substrates were buried in peat soil at a depth of $10 \mathrm{~cm}$ from the surface.
\end{abstract}

Results: The results demonstrated that latent fingermarks could be effectively recovered after being buried in the soil up to 8 weeks using Sudan black. The position of the substrates whether underlying in "face up" or "face down" orientations when buried had also influenced the quality of the developed fingermarks. Fingermarks buried in the "face up" position demonstrated better quality and more ridge details as compared to those buried in the "face down" position. Secondary fingermarks were also observed in this study and found to be useful for identification and must be taken into consideration when developing fingermarks on buried items in forensic cases.

Conclusion: The development of fingermarks recovered from burial environments is feasible as excellent ridge characteristics can still be identified. Hence, any evidence recovered from burial sites should be examined for fingermarks and cannot be discounted.

Keywords: Fingermarks, Burial, Soil, Chemical enhancement, Sudan black

\section{Background}

Fingermarks are one of the most important forms of physical evidence in criminal investigations and the most commonly encountered evidence at the scene of a crime (Cadd et al. 2015). Latent fingermark is the most common

\footnotetext{
* Correspondence: nikf@usm.my

${ }^{2}$ Forensic Science Programme, School of Health Sciences, Universiti Sains

Malaysia, Kubang Kerian, Kota Bharu, Kelantan, Malaysia

Full list of author information is available at the end of the article
}

and challenging type of fingermark to be detected due to its nearly invisible characteristics (Voss-De Haan 2006). Such residues are somehow fragile and can be degraded when exposed to extreme conditions such as direct physical contact, heat, moisture, and contaminants. On the other hand, changing the composition of the fingermark also dictates the choice of the fingermark development method.

\section{Springer Open}

(c) The Author(s). 2020 Open Access This article is licensed under a Creative Commons Attribution 4.0 International License, which permits use, sharing, adaptation, distribution and reproduction in any medium or format, as long as you give appropriate credit to the original author(s) and the source, provide a link to the Creative Commons licence, and indicate if changes were made. The images or other third party material in this article are included in the article's Creative Commons licence, unless indicated otherwise in a credit line to the material. If material is not included in the article's Creative Commons licence and your intended use is not permitted by statutory regulation or exceeds the permitted use, you will need to obtain permission directly from the copyright holder. To view a copy of this licence, visit http://creativecommons.org/licenses/by/4.0/. 
In many cases, criminals try to dispose of the evidence in several ways, such as throwing into the water (Trapecar 2012a; Trapecar 2012b; Sodhi and Kaur 2012), cast into extreme heat (Dominick et al. 2011), or buried in the soil (Cullen et al. 2010; Tumer et al. 2013) to avoid detection from the law enforcement agencies. Such actions may cause the evidence to be defaced and destroyed and loss of trace evidence including fingermarks. Soil burial is a standard method chosen by the criminals for the disposal of weapons, clothes, documents, and human remains. These exhibits are only recovered or excavated after days, weeks, or even months since the burial. Therefore, some exhibits may lose their evidential value due to the degradation and contamination in the soil. It is expected that fingermarks in the burial condition suffer and degrade similarly to the decomposition of buried biomaterials. Due to the complex nature of the soil, forensic evidence exposed to the burial condition is subjected to numerous uncontrolled variables. Hence, it is an extremely challenging task to investigate all the dependencies thoroughly. Besides, most crime scene officers have the misconception that no fingermarks can ever be developed due to the physical contact with the soil particles and possible chemical reactions between fingermark compositions and the contaminants in the soil. More study is required to explore the influences of soil on forensic evidence, particularly on fingermarks recovered from buried substrates. The understanding of the changes of fingermark composition and aged fingermarks in burial conditions may help in determining the most appropriate techniques in developing such fingermarks.

Many studies had reported on the development of fingermarks from different types of substrates or surfaces and under various challenging conditions, such as latent fingermarks exposed to water (Rohatgi and Kapoor 2016; Jasuja et al. 2015) and extreme temperature (Dhall et al. 2013; Gardner et al. 2016), contaminated by blood (Bossers et al. 2011; Praska and Langenburg 2013), and fingermarks on the sticky side of adhesive tapes (Jasuja et al. 2007) and fired brass cartridge cases (Nizam et al. 2012). Also, there are volumes of research conducted concerning the ageing of fingermarks (Archer et al. 2005). However, there is no information available in the literature with regard to the development of fingermarks on buried objects. Hence, the extent of the influence of the burial environment, such as soil on fingermarks on the buried substrate, is not well understood.

This study was carried out as an attempt to investigate and provide more scientific information regarding the quality and survivability of latent fingermarks on a buried metal substrate and its implication on the development and enhancement methods. This research may be of significant importance in several ways. It provides contemporary and better information regarding the persistence of latent fingermarks that have been exposed to the soil over specific periods and the possibilities of recovering latent fingermarks from the buried exhibits by using the most effective chemical enhancement.

\section{Methodology}

\section{Substrates}

Stainless steel metal plate was chosen as the substrate for fingermark deposition in this study as analogous to metal exhibits that are commonly encountered at crime scenes such as knife, machete, firearms, or any metal objects. Metal plates were chosen because they were resistant to the soil and extreme outdoor conditions. The metal plates used were $10 \mathrm{~cm} \times 10 \mathrm{~cm}$ in size (Fig. 1). In total, 92 stainless steel plates were utilised throughout this study.

\section{Fingermark deposition and sample preparation}

Sebaceous fingermarks were used throughout the experiment according to the guidelines recommended by the International Fingerprint Research Group (IFRG) (International Fingerprint Research Group (IFRG) 2014). The guidelines, however, are not meant to be prescriptive (Azman et al. 2018). The donor was asked to wash hands thoroughly. Prior to fingermark deposition, the metal plates were cleaned using acetone to remove contaminants and then dried using a clean tissue. The cleaned metal plate was placed on the weight scale, and the donor was asked to touch the face with the thumb to obtain the sebum on the fingertip. The fingermark was deposited on the substrate with exerted pressure or equivalent weight of $500 \mathrm{~g}$. Fingermarks were deposited in replicate on each metal plate.

\section{Fingermark development}

In this study, a preliminary experiment was carried out to determine the most effective chemical for latent

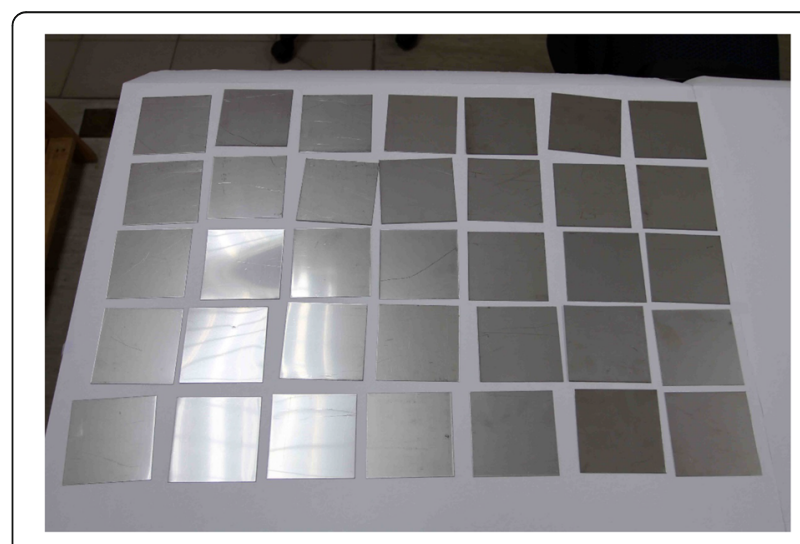

Fig. 1 Metal plates used in the study 
fingermark development on the buried metal plates prior to the main experiment. Five different chemicals were used to develop and enhance the latent fingermarks on the metal plates, namely fingermark powder dusting, small particle reagent (SPR), Sudan black, oil red O, and crystal violet. All procedures were conducted according to the established techniques as described in the literature (Home Office 2017).

\section{Fingermark powder dusting}

A small amount of fingerprint powder (Sirchie Heavy Black Hi-Fi Volcano) was applied onto the surface of the substrate by using a brush. The powder was applied with light brushing action until the fingermarks were visible and reached a point of sufficient clarity. The excess powder was gently removed using a brush. Caution was required when applying or removing the powder as the contact of the brush with the fingermark may cause smudging to the fingermarks.

The images of developed fingermarks were taken prior to lifting. Oblique light was applied to illuminate the developed fingermarks in order to increase contrast for better resolution during the photography. The developed fingermarks were then lifted using fingerprint lifting tapes and fixed on backing cards for preservation and comparison. Throughout this study, Sirchie ${ }^{\circ}$ Rubber-jell $^{\mathrm{mx}}$ lifting tapes were used to preserve the developed fingermarks contaminated with soil. This lifting tape contains a transparent and elastic rubber/jell lifter sheet on its sticky side. The elastic property of the rubber/jell lifter sheets can minimise the formation of air pockets by engulfing the particles found on the surface.

\section{Small particle reagent}

Premixed SPR (Sirchie) was utilised to develop the latent fingermark deposited on the metal plates. SPR solution was sprayed onto the substrate surface and rinsed gently with deionised water to remove the excess solution. The spraying and rinsing processes were repeated to achieve the desired ridges' detail and clarity. Once the desired result was obtained, the metal substrates were allowed to air dry at room temperature, and the fingermarks were lifted with adhesive fingerprint lifting tape and preserved on the fingerprint backing card.

\section{Sudan black}

Fifteen grams of Sudan black was mixed with $1000 \mathrm{~mL}$ of ethanol and stirred until the solution was thoroughly mixed. Five hundred millilitres of distilled water was added into the mixture and stirred to produce the working solution. The solution was then kept in the dark bottle prior to use.

The working solution was shaken before the application. A sufficient amount of Sudan black solution was poured into a glass tray. The metal plates bearing the latent fingermarks were immersed in the Sudan black solution for $10 \mathrm{~min}$. The plates were then removed and rinsed using deionised water to remove excessive Sudan black solution. Specimens were allowed to dry at room temperature. The developed fingermarks appeared blueblack. The processes were repeated to increase the contrast of the developed fingermarks.

\section{Oil red 0}

Two types of solutions were prepared for this method: the developer and the $\mathrm{pH} 7$ buffer. For the preparation of the developer solution, $1.54 \mathrm{~g}$ of oil red $\mathrm{O}$ was weighed and dissolved in $770 \mathrm{~mL}$ of methanol; $9.2 \mathrm{~g}$ of sodium hydroxide was dissolved in $230 \mathrm{~mL}$ of distilled water and then added into the first solution. The mixture was placed on an electric stirrer for $20-30 \mathrm{~min}$. The mixture was filtered and stored in an amber glass bottle wrapped with aluminium foil to keep the solution away from light.

The $\mathrm{pH} 7$ buffer solution was prepared by adding $26.5 \mathrm{~g}$ of sodium carbonate $\left(\mathrm{Na}_{2} \mathrm{CO}_{3}\right)$ to $2 \mathrm{~L}$ of distilled water and shaken until dissolved; $20.13 \mathrm{~mL}$ of concentrated nitric acid $65 \%\left(\mathrm{HNO}_{3}\right)$ was carefully added into the solution. Finally, distilled water was added to increase the volume to $2.5 \mathrm{~L}$. A pH metre was used to measure the buffer solution to ensure that the desired $\mathrm{pH}$ was achieved. Additional sodium carbonate was added to increase the $\mathrm{pH}$ level if the result was lower than the expected $\mathrm{pH}$, and nitric acid was added to decrease the $\mathrm{pH}$ level.

In the fingermark development process, the metal substrates were placed in a stain-resistant tray, and the developer solution was added to submerge the substrate. The tray was then placed on an electric shaker for 60 min or until the fingermarks were clearly observed. The metal substrates were then removed and placed in a clean tray containing the buffer solution. Finally, the substrates were rinsed with distilled water and allowed to be air dried. Image of developed fingermarks was taken before and after the lifting.

\section{Crystal violet}

One hundred millilitres of distilled water was carefully added into the beaker containing $1.0 \mathrm{~g}$ crystal violet powder. A magnetic stirrer was used to dissolve the crystal violet. The metal substrates bearing the latent fingermarks were immersed in the crystal violet solution for 10 to 15 min or until the marks were clearly visible. The metal substrates were removed and rinsed with deionised water and then air dried. The images of developed fingermarks were taken before and after the lifting. 


\section{Preliminary experiment}

A preliminary experiment was conducted to determine the most effective method for fingermark development on the buried metal plates. This experiment was carried out indoor under controlled conditions in the laboratory. The peat soil sample was obtained from the selected area and filtered using a 5-mm mesh sieve to exclude rocks, roots, plant fragments, organisms, and any unwanted foreign materials. The soil was stirred and homogenised prior to filling into the boxes.

A total of 35 metal plates bearing the fingermarks were placed underlying in the "face down" position on the first layer of the soil (Fig. 2). The second layer of soil was gently poured into the boxes to cover the samples until it reached approximately $10 \mathrm{~cm}$ depth from the surface. The metal plate samples were collected daily for fingermark development using five selected chemicals for seven consecutive days. All images of the developed fingermarks were taken before and after the lifting. Lifted fingermarks were kept and preserved for comparison purposes.

\section{Main experiment}

The main experiment was carried out to simulate the realistic situation in which the metal plates bearing the fingermarks were buried in the soil at various burial time intervals for up to 2 months. This experiment was conducted outdoor to mimic the real case scenario.

The burial location was chosen from the same area where the soil sample was collected in the preliminary experiment. The type of soil was peaty soil or organic soil. The chosen location was a shady area under the trees with a flattened ground surface. A small area of approximately $1 \mathrm{~m} \times 2 \mathrm{~m}$ at the sampling location was allocated for this study. The herbs, roots, rocks, and other unwanted foreign materials on the surface were removed. The soil was dug approximately $15 \mathrm{~cm}$ deep, and the soil was filtered using a 5-mm mesh sieve to remove

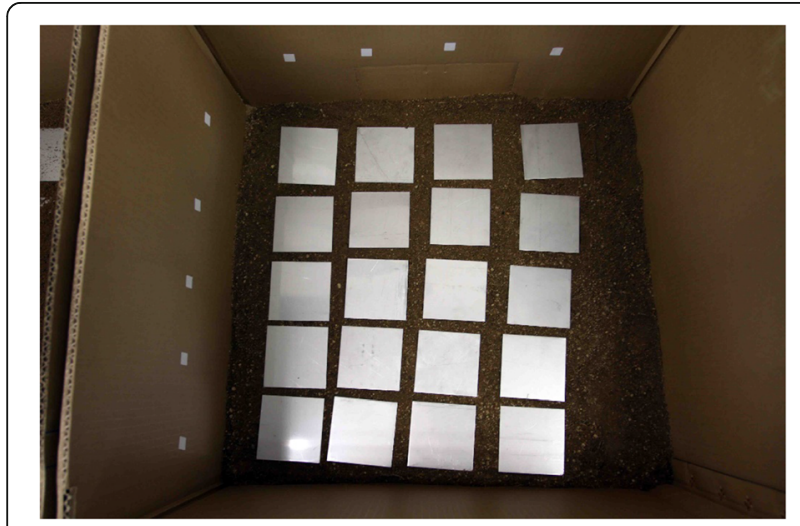

Fig. 2 Metal plates were placed on the first layer of the soil after latent fingermark depositions rocks, roots, and foreign materials. An attempt was made to homogenise the soil sample to minimise variations.

The first layer of the filtered soil was filled into the pit and flattened using a 1-m ruler. Metal plates bearing the latent fingermarks were placed and arranged on the first layer of the soil. A $20-\mathrm{cm}$ stick was placed next to each metal plate as a location indicator, and each stick was marked with a depth indicator. The second layer of filtered soil was carefully filled into the pit to cover the metal plates. These substrates were buried at $10-\mathrm{cm}$ depth from the soil surface (Fig. 3). Soil samples were also collected for $\mathrm{pH}$ and moisture determination.

In this part of the experiment, four series of the sample was buried at the sampling location, and each series consisted of 13 metal plates. The first and second series of the stainless steel plates were buried with fingermarks underlying in "face up" and "face down" positions, respectively. All samples were buried at the same depth $(10 \mathrm{~cm})$ in the same vicinity (Fig. 4a, b).

Metal plate samples bearing the latent fingermarks were excavated daily for analysis in the first week, and subsequent excavations were performed on days 10, 14,

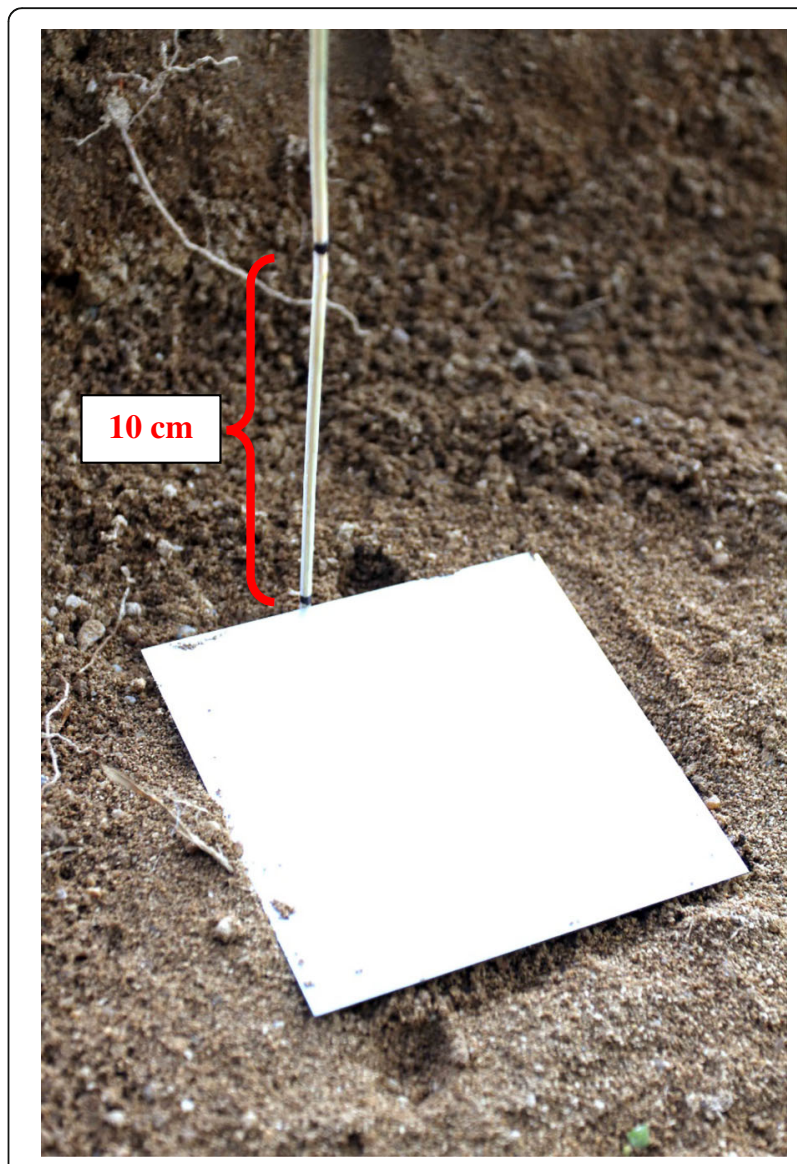

Fig. 3 The stick used as location and depth indicator 


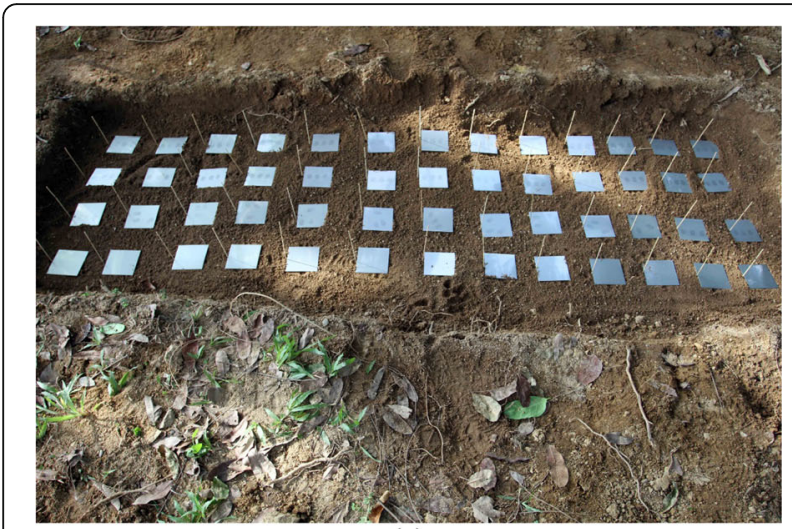

(a)

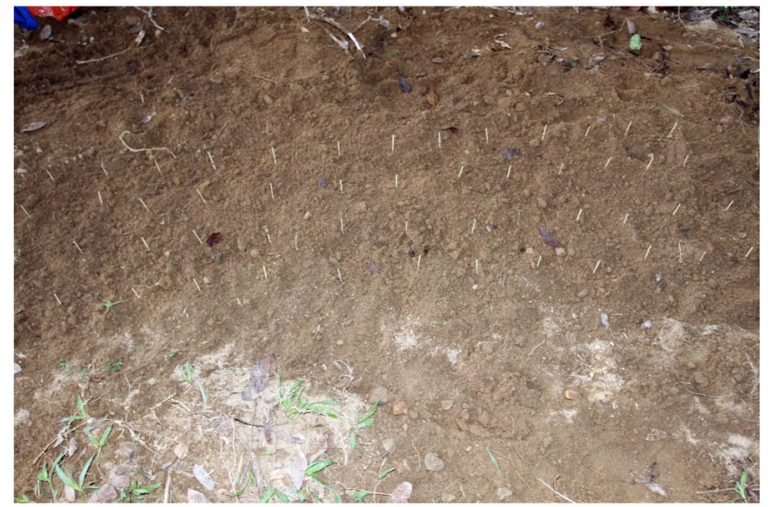

(b)

Fig. 4 Metal plates were placed on a the first layer of soil and covered with b 10-cm-thick second layer soil

$21,28,42$, and 56 . During the excavation process, the soil was dug gently with a garden rake to avoid scratching the surface of the metal plates bearing the fingermarks. The recovered metal plates were then transferred to the laboratory for fingermark development using the most effective chemical, as determined in the preliminary experiment. Prior to any fingermark development, the condition of the recovered metal plates was observed and noted. The air blower was used to clean up the surface from the soils and other contaminants. The images of developed fingermarks were taken before and after the lifting with a digital single-lens reflex camera. The second lifting of the fingermarks was also carried out whenever possible.

\section{Assessment of developed fingermarks}

The developed fingermarks in this study were assessed qualitatively with the visual observation by converting the visual appearance of the fingermarks to a numerical value. The scoring system (Table 1) was used to evaluate the quality and clarity of the ridge detail and minutiae of the developed marks throughout the study (Champod et al. 2004).
Table 1 The fingermark quality scale used in the assessment of developed fingermarks

\begin{tabular}{ll}
\hline Grade & Description \\
\hline 0 & No visible mark \\
1 & $\begin{array}{l}\text { Poor quality, very few visible ridges } \\
2\end{array}$ \\
3 & $\begin{array}{l}\text { Poor quality, some ridge detail visible or partial mark with } \\
\text { Reasonable quality, ridge detail and some characteristics visible, } \\
\text { identification possible }\end{array}$ \\
4 & $\begin{array}{l}\text { Good quality mark, ridge detail and characteristics visible, } \\
\text { probable identification }\end{array}$ \\
5 & Excellent quality, full mark very clear, identification assured \\
\hline
\end{tabular}

\section{Results and discussion}

\section{Preliminary experiment}

In this experiment, five chemicals, namely powder dusting, small particle reagent (SPR), Sudan black, crystal violet, and oil red $\mathrm{O}$, were tested to develop fingermarks on metal plates buried in soil under a controlled condition for seven consecutive days. The most effective chemical was chosen for the main experiment based on the quality of the developed fingermarks using the grading system.

It was demonstrated that different chemicals and time intervals for exposure contributed to a different outcome of the resultant fingermarks (Trapecar 2012b). Highquality developed fingermarks are associated with the specific chemicals used and the age or time since deposition of the fingermarks. In this study, the complexity and numerous variables in the soil would play a significant role that determined the quality of the developed fingermarks.

\section{Fingermark powder dusting}

The quality of fingermarks developed with the powder dusting method was good for the first 2 days of the burial period with visible and sufficient ridge details (Fig. 5). Water speckles were observed on most of the recovered fingermarks and had deteriorated the quality of the recovered marks as the burial period increased (Fig. 6). First level and second level details can still be visualised at the early stage of the experiment that allowed positive identification, but noted to be declined dramatically from day 5 of the burial duration.

The quality of the fingermarks was also thought to be influenced by the condition of the substrate's surface (Cadd et al. 2015). The metal substrates were contaminated by soil particles during the burial period. Although most soil particles had been removed by using air blower prior to development, some particles were still present and adhered to the surface of the metal substrates. During the development process, the particles may have destroyed and abraded the ridge detail due to the 


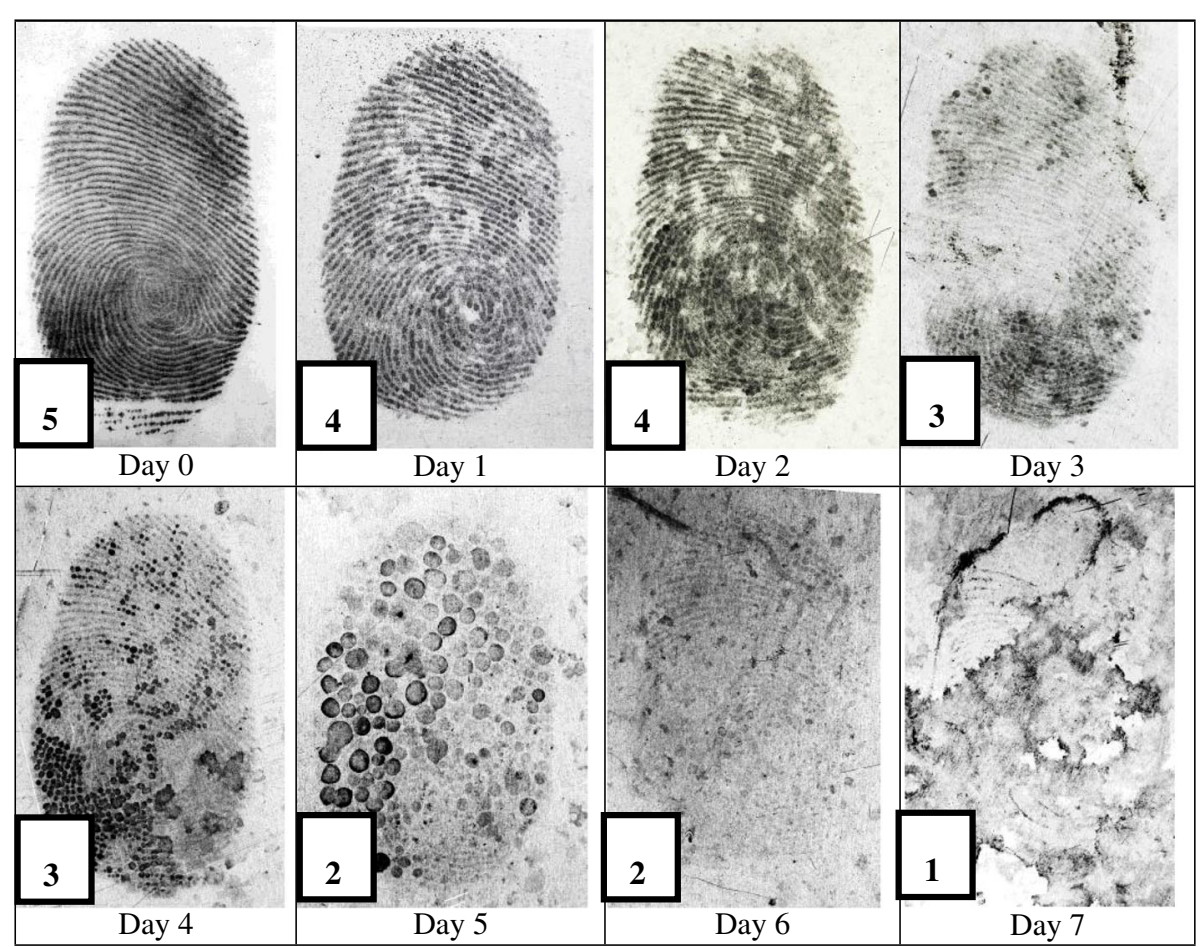

Fig. 5 Developed fingermarks using black powder dusting

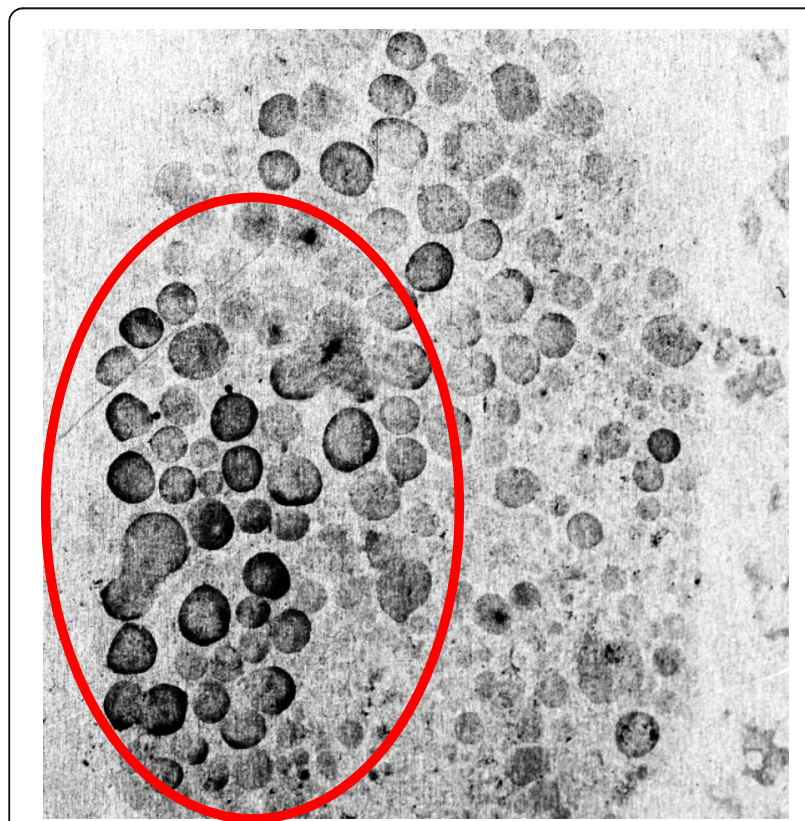

Fig. 6 Water speckles observed on developed fingermark brushing motion during powdering (Fig. 7). An effort had been made to gently brush the fingermarks with an appropriate amount of fingerprint powder to minimise any potential destruction.

\section{Small particle reagent}

Excellent clarity of the developed fingermarks was obtained using small particle reagent for fingermarks on metal substrates buried in shorter periods. However, the quality of developed fingermarks degraded as a function

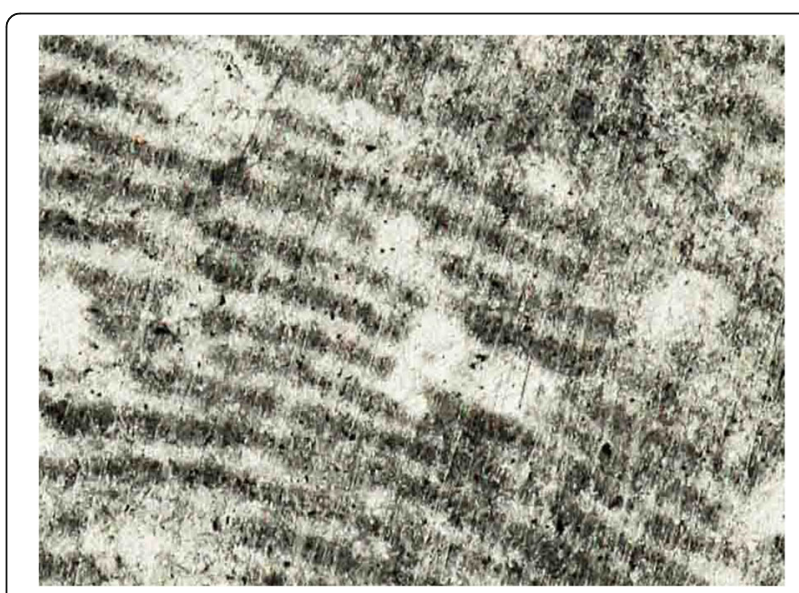

Fig. 7 The abrasion of ridge detail observed on developed fingermarks after powder dusting due to soil particles 
of burial duration (Fig. 8). Water speckles were also encountered on the developed fingermarks after the exposure to a prolonged burial environment. These had masked most of the ridge detail, despite the lipid sensitive nature of small particle reagent. It was thought that moisture might have dissolved the water-soluble components of the fingermark composition such as amino acids, calcium, magnesium, and sodium and left behind the lipid components (Friesen 2015; Dewes et al. 2006).

Small particle reagent was previously proven to be an effective method in developing fingermarks exposed to the water environment and dust (Voss-De Haan 2006). The small particle reagent was sprayed on the substrate gently, and the solution was allowed to flow through the fingermarks. Such a condition allowed the soil particles on the surface to be "washed" off without introducing any direct physical contact on fingermarks. Therefore, further destruction of fingermarks can be avoided. However, in this study, the loss of clarity of fingermarks was evident, and this destruction was due to the burial environment and its interaction with the residues of fingermarks.

\section{Sudan black}

Latent fingermarks on the metal plates buried in the soil under controlled conditions were successfully developed using Sudan black. Figure 9 shows the images of the developed fingermarks from day 0 to day 7 of the burial period. The fingermarks of good quality were developed using this chemical throughout the experiment. Water speckles from the burial environment were also observed on most of the recovered fingermarks. However, ridge details can still be observed on the fingermarks after the exposure to the burial environment for up to 7 days.

The results demonstrated that Sudan black did stain not only the fingermark ridges but also the background, which appeared blue-black but at a lower intensity. The staining of the background and formation of the water speckles may indicate that Sudan black did not only react with the lipid components in fingermark residue, but it may also have an affinity to other chemical compounds in the soil resulting in a few masked ridge details.

\section{Oil red 0}

The images of fingermarks developed using oil red $\mathrm{O}$ are shown in Fig. 10. The developed fingermarks for the first day of the burial period appeared in intense red. However, the quality had deteriorated dramatically as ridge details in fingermarks were lost from day 2 onwards in the burial condition. The presence of water speckles on most fingermarks was prevalent and had deteriorated the clarity of the ridges. General ridge path can be seen at the early period of burial but declined gradually along with the consecutive day intervals. From day 4 of burial, only the outline of fingermarks with limited ridge details

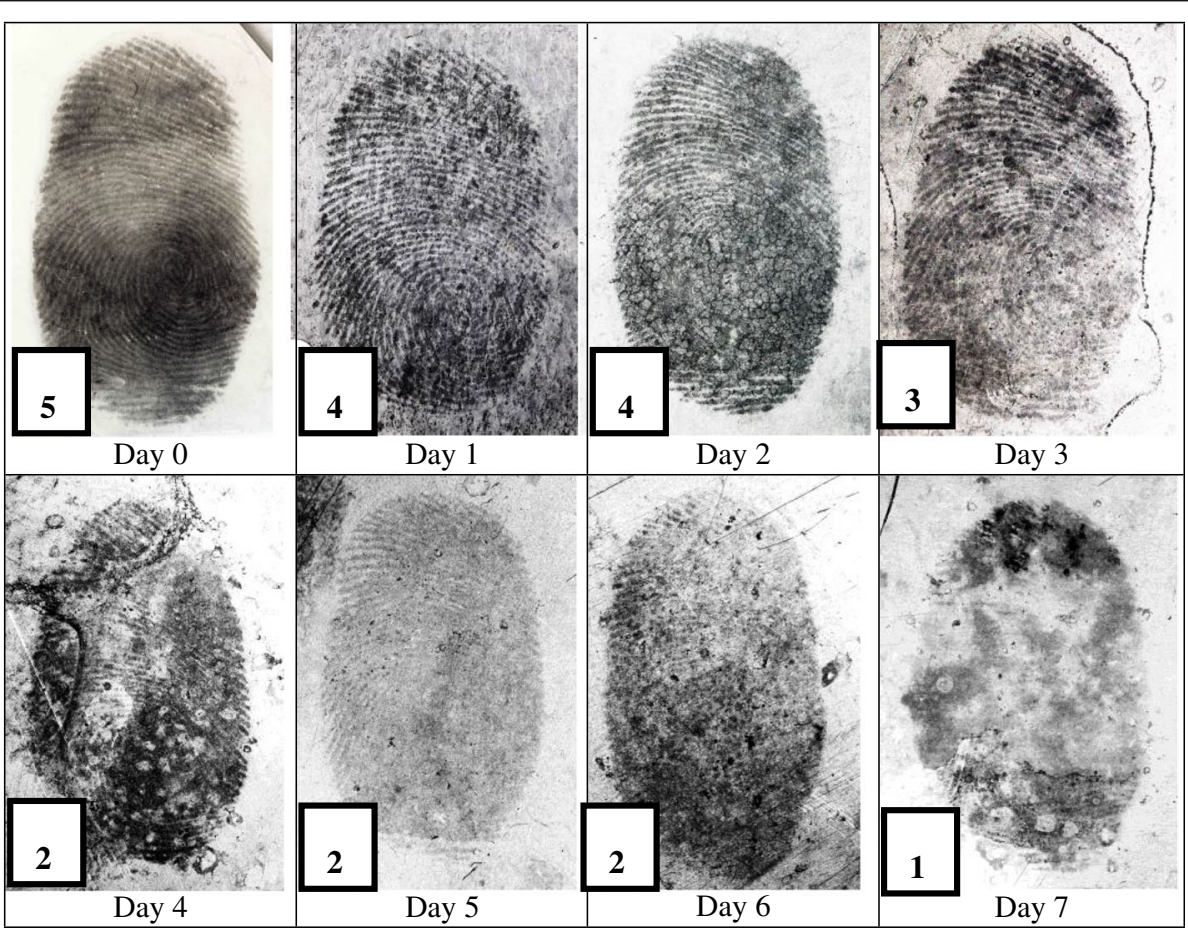

Fig. 8 Developed fingermarks using small particle reagent 


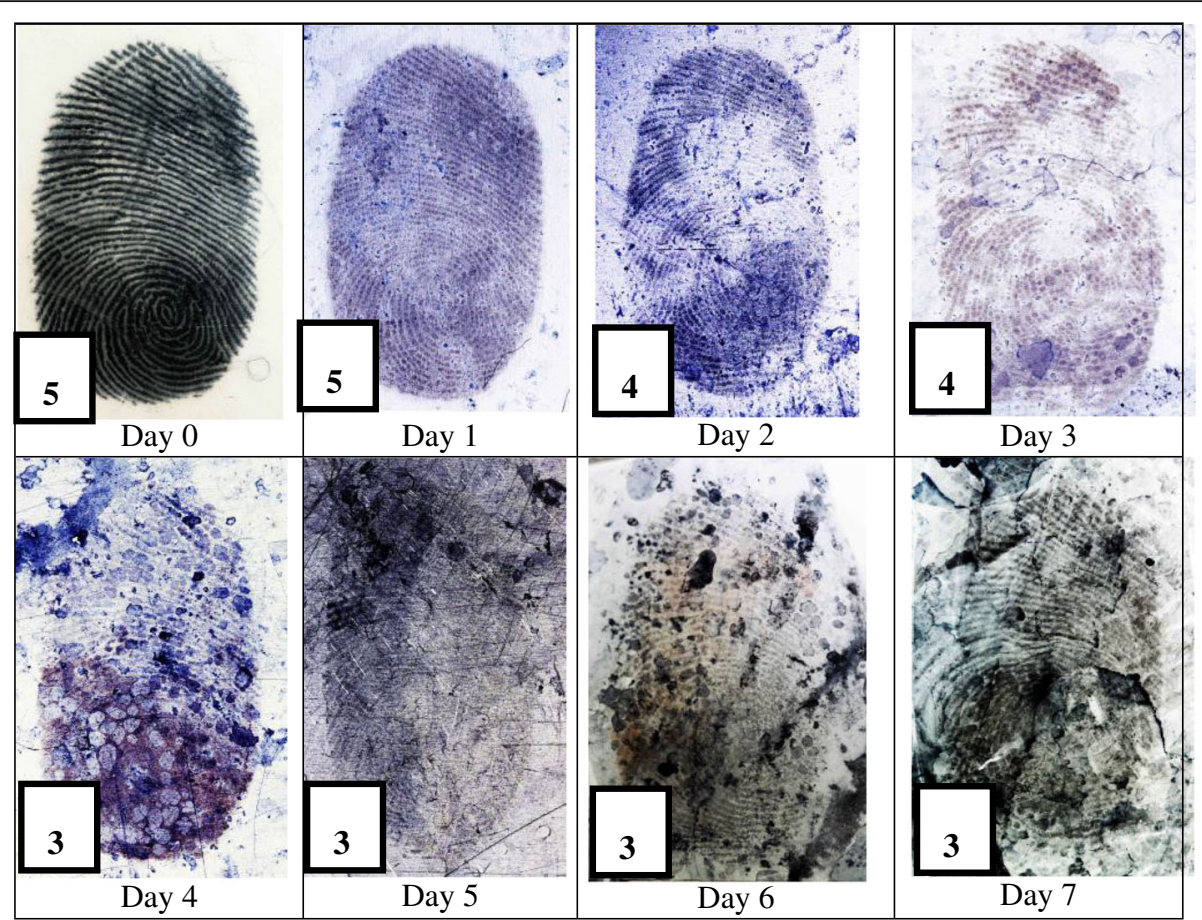

Fig. 9 Developed fingermarks using Sudan black

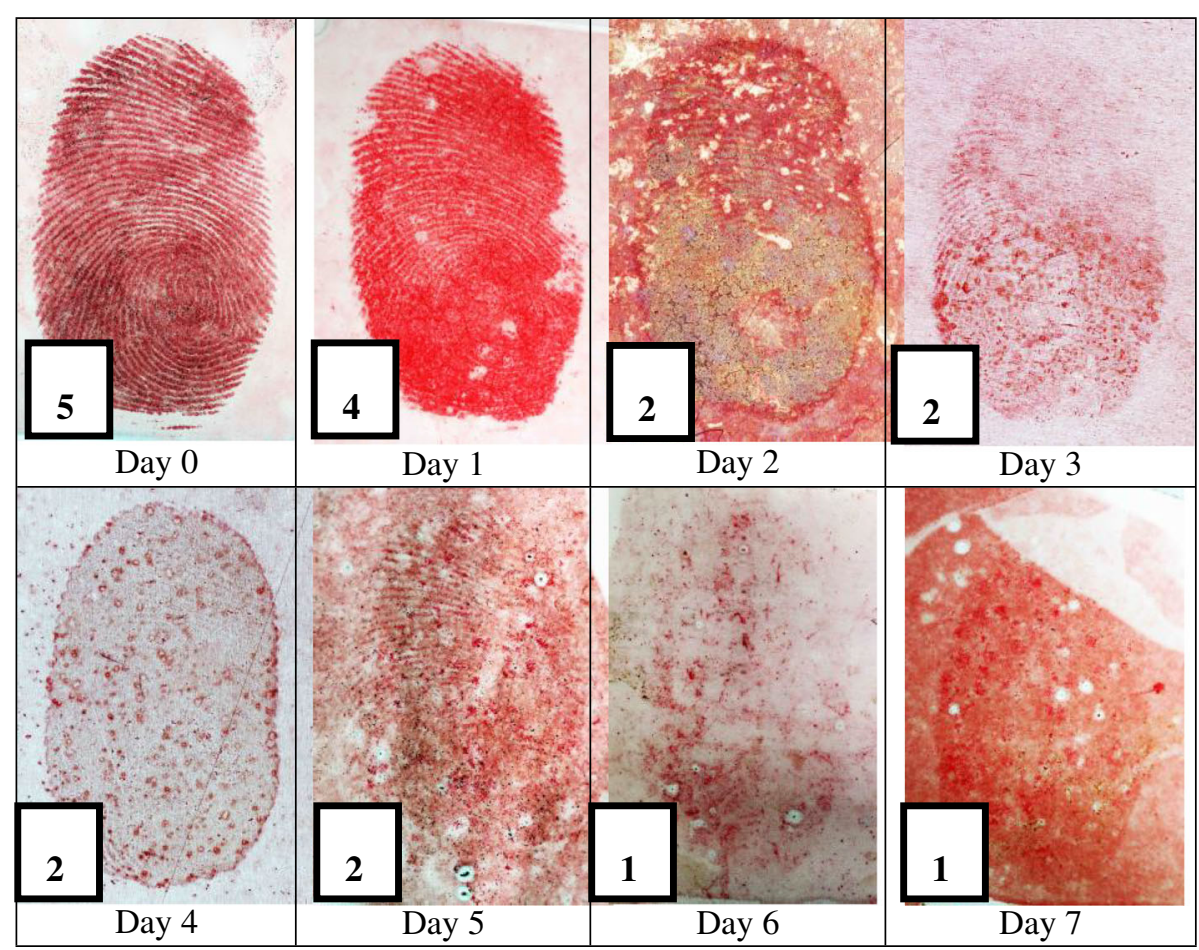

Fig. 10 Developed fingermarks by using oil red $O$ 
was observed. The quality of the fingermarks developed using the oil red $\mathrm{O}$ method was poor and proven not to be a suitable method to develop fingermarks found in the burial environment. The poor quality of fingermarks developed using oil red $\mathrm{O}$ may be due to its ineffectiveness on non-porous objects. Previous studies had demonstrated that oil red $\mathrm{O}$ was effective in developing fingermarks on both porous and non-porous substrates (Beaudoin 2004; Kelly 2019).

\section{Crystal violet}

Fingermarks developed using crystal violet yielded poor quality throughout the preliminary experiment (Fig. 11). Very faint fingermarks with fewer visible ridges were observed on the metal plates recovered within 3 days of the burial period. No visible ridge details were observed on subsequent day intervals. Although lower interference was observed as compared to other chemicals, most fingermarks developed using crystal violet had very poor clarity and lower visibility score. The results suggested that crystal violet is not suitable for developing latent fingermarks on buried metal substrates.

\section{The most effective method}

The comparative assessments of the fingermarks developed using five different chemicals in the preliminary experiment indicated that different chemical enhancements yielded different results. Throughout the experiment, Sudan black had produced the best quality of fingermarks in comparison with other chemicals. Ridge details can still be seen after prolonged burial in soil up to 7 days. Powder dusting and small particle reagent produced an acceptable quality of developed fingermarks at the early stage of the experiment, but the quality deteriorated from day 3 onwards. Hence, they are not recommended for developing latent fingermarks on buried items. Powder dusting and small particle reagent can be employed as alternative methods to develop such fingermarks due to their simplicity in the application, which can be applied in situ, particularly for the substrates that were freshly buried in real case scenario. The fingermarks developed using oil red $\mathrm{O}$ and crystal violet yielded poor quality ridge details and produced the fewest usable fingermarks. Thus, these methods are not recommended for developing fingermarks on buried non-porous substrates.

Most of the fingermarks developed in the preliminary experiment were affected by the formation of water speckles. Although this experiment was conducted indoor and had no direct influence from environmental insults such as weather, yet the interferences were difficult to eliminate due to the complex composition of the soil. Figure 12 depicts the overall quality of the developed fingermarks using various chemical enhancements in the preliminary experiment.

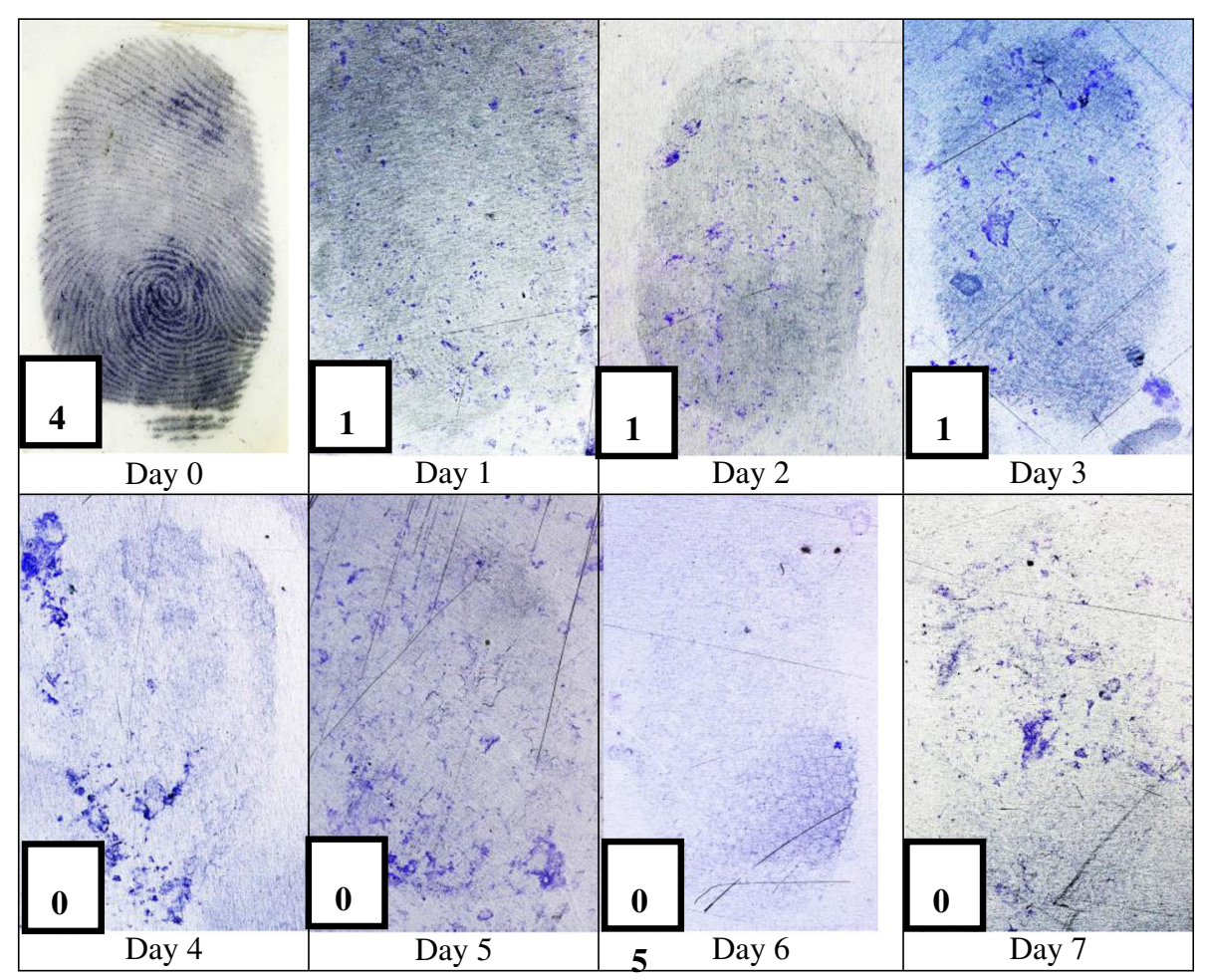

Fig. 11 Fingermarks developed using crystal violet 


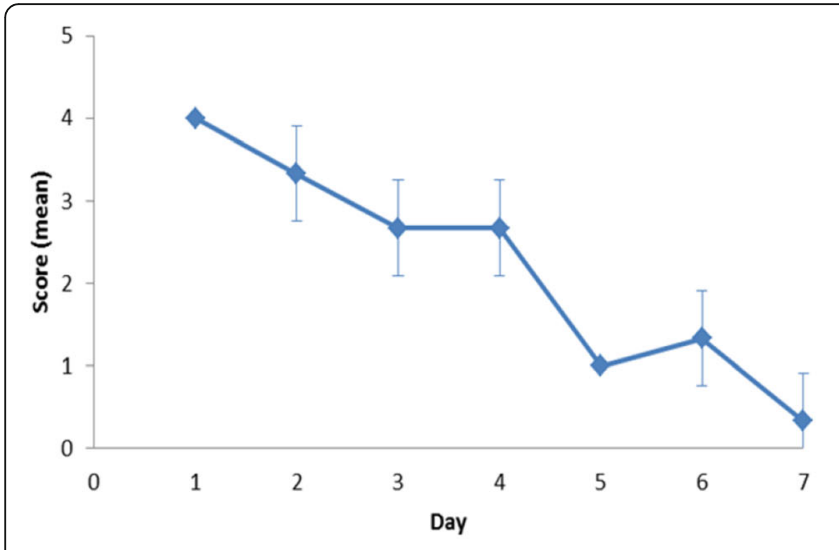

(a)

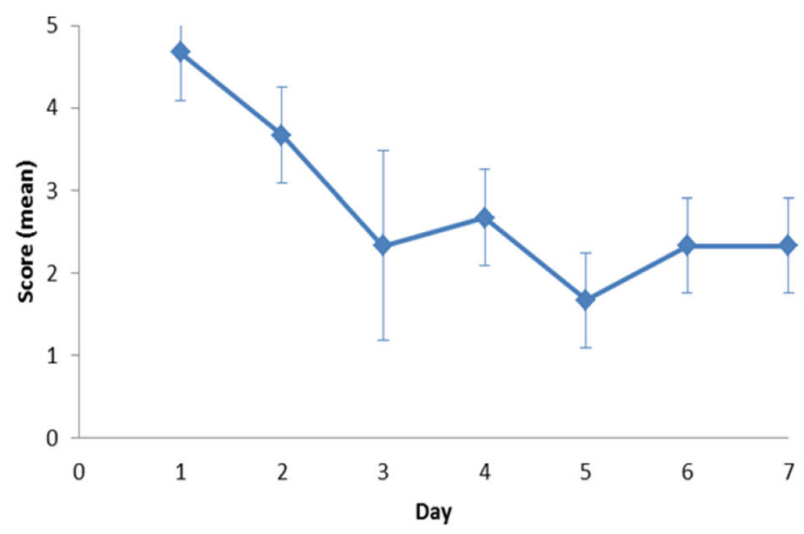

(c)

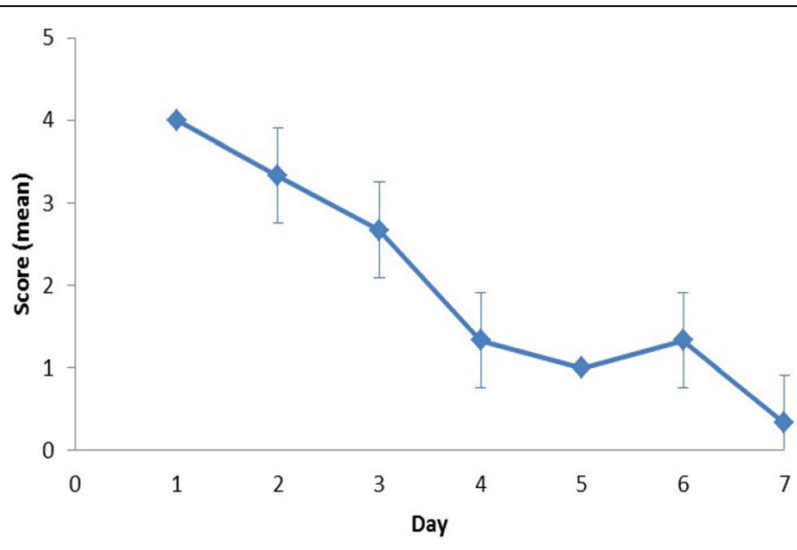

(b)

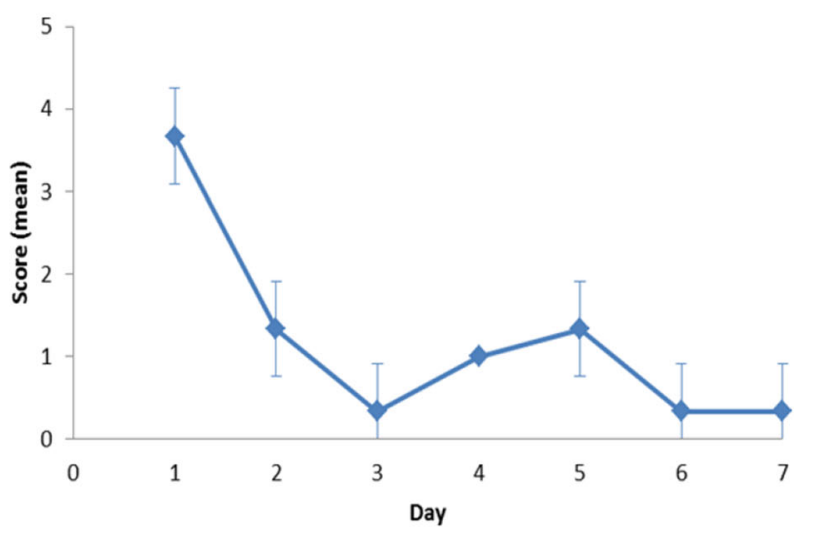

(d)

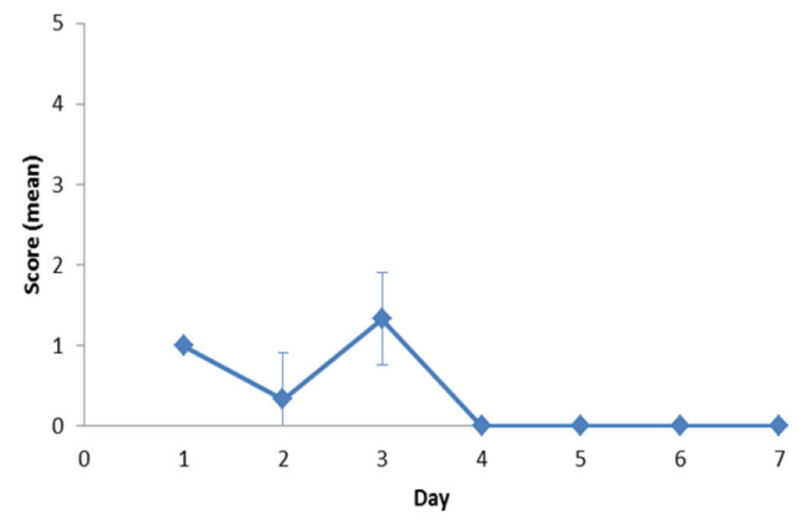

(e)

Fig. 12 The quality of developed fingermarks based on the visibility score using a powder dusting, b small particle reagent, c Sudan black, $\mathbf{d}$ oil red $\mathrm{O}$, and e crystal violet

The quality of the developed fingermarks was related to the chemical used (Trapecar 2012b). Every chemical enhancement has its characteristics and affinity to the specific compound in the fingermark composition. However, different chemicals may also react differently to different types of substrates. In this experiment, the fingermarks recovered on day 0 were developed using all five chemicals as control samples. All chemicals produced very good fingermarks when tested in their fresh state (day 0 ). 


\section{Main experiment}

The main experiment was conducted outdoor to simulate real casework. Hence, various uncontrolled variables were expected attributable to the burial environment. Based on the evaluation conducted in the preliminary experiment, Sudan black was proven to be the most effective chemical for enhancing fingermarks on metal plates buried in the soil. Therefore, Sudan black was chosen for developing all recovered latent fingermarks in the main experiment.

Several factors were also taken into consideration in the main experiment with regard to the results observed in the preliminary experiment. In the preliminary experiment, the metal plates bearing the fingermarks were buried underlying in "face down" position resulted in the accumulation of water speckles on the bottom surface of the metal plates due to the condensation of moisture in the soil (Fig. 13). The formation of water speckles on the surfaces of metal plates had greatly affected the quality of the recovered fingermarks, as demonstrated in the preliminary experiment. No water accumulation was observed on the "face up" surface of the metal plates. Therefore, in the main experiment, two sets of metal plates bearing the fingermarks were prepared and buried in both orientations, i.e. "face up" and "face down" for comparison purposes.

Excavation of the buried metal plates bearing the fingermarks was performed with extra care throughout the burial intervals by digging the soil from the side where the indicator sticks were placed (Fig. 14). The upper layer of the soil was carefully removed, especially for the metal plates bearing fingermarks deposited in the "face up" position. Water speckles were observed, and more

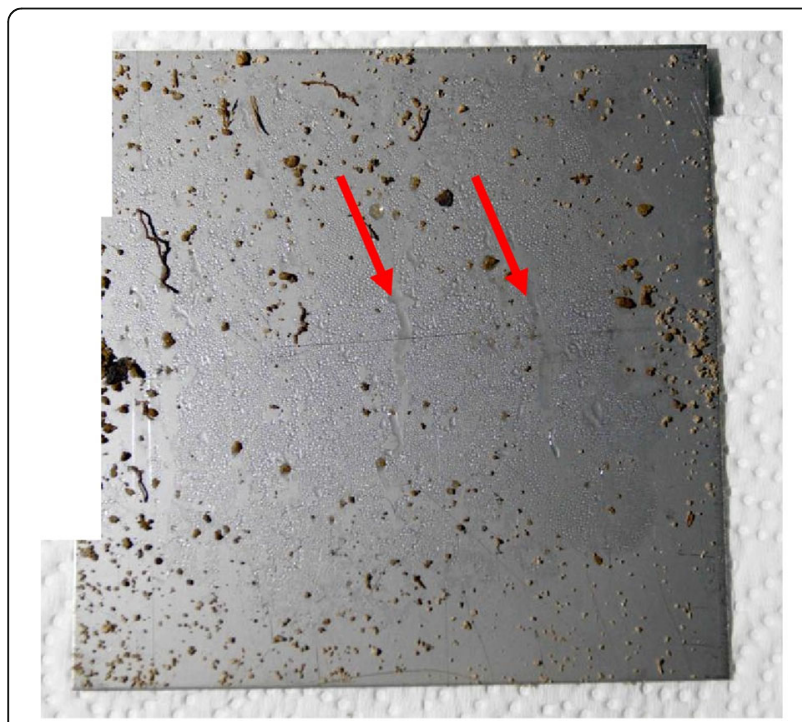

Fig. 13 The formation of water speckles on metal plates bearing the fingermarks ("face down")

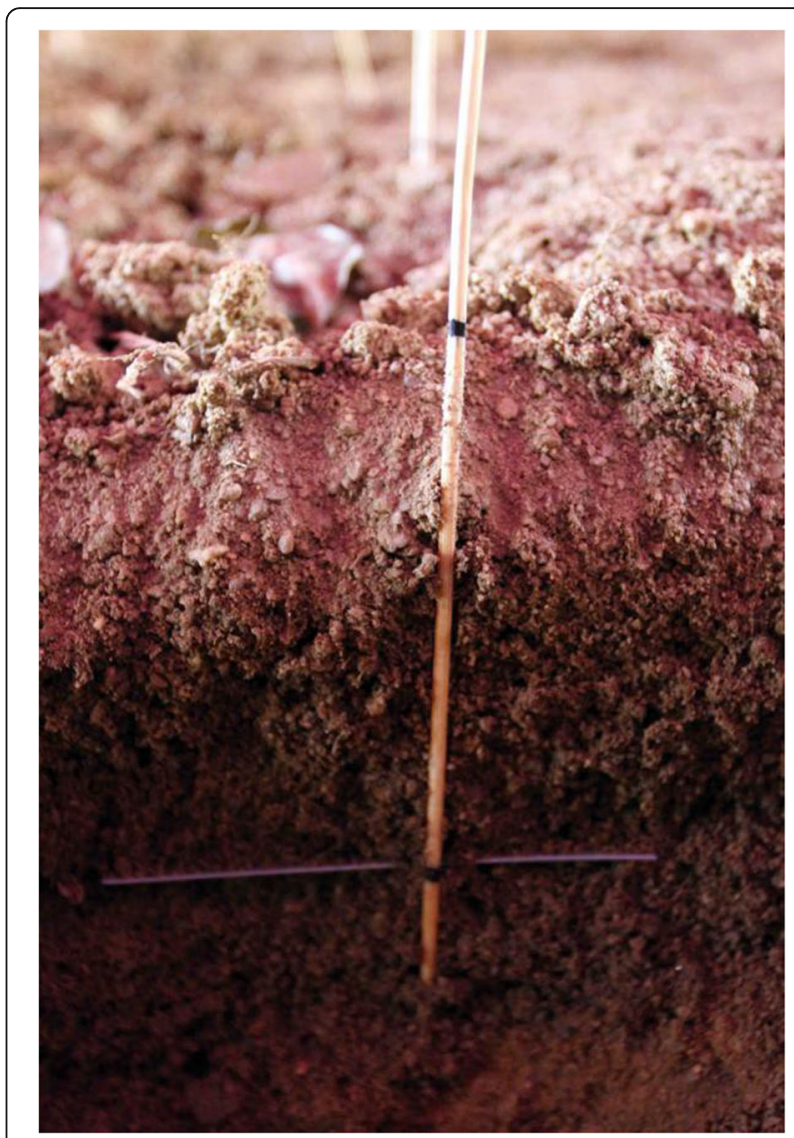

Fig. 14 Metal plate was excavated by digging from the side as indicated by the stick

wet soil particles were adhered to the "face down" surface of the metal plates as compared to the "face up" surface. All excavated metal plates were allowed to air dry in the laboratory prior to the development process. Soil particles adhered to metal plates bearing fingermarks were carefully removed by using a blower. However, some soil deposits on the metal plates were difficult to remove due to strong adhesion. During the development process, metal plates were submerged into Sudan black solution, and some soil deposits and particles were dissolved and washed off during this process resulting in fingermarks of better quality.

\section{Fingermarks on buried metal plates}

Figure 15 illustrates the images of fingermarks developed on the "face up" surface of the metal plates. The quality of the recovered fingermarks was excellent throughout the experiment. Fingermarks were detected, and the general ridge path can be seen even after 8 weeks of the burial period. Sudan black had produced clear and sufficient ridge details of fingermarks during the first 3 weeks of the burial period. However, the quality of the fingermarks had deteriorated from the fourth week onwards. 


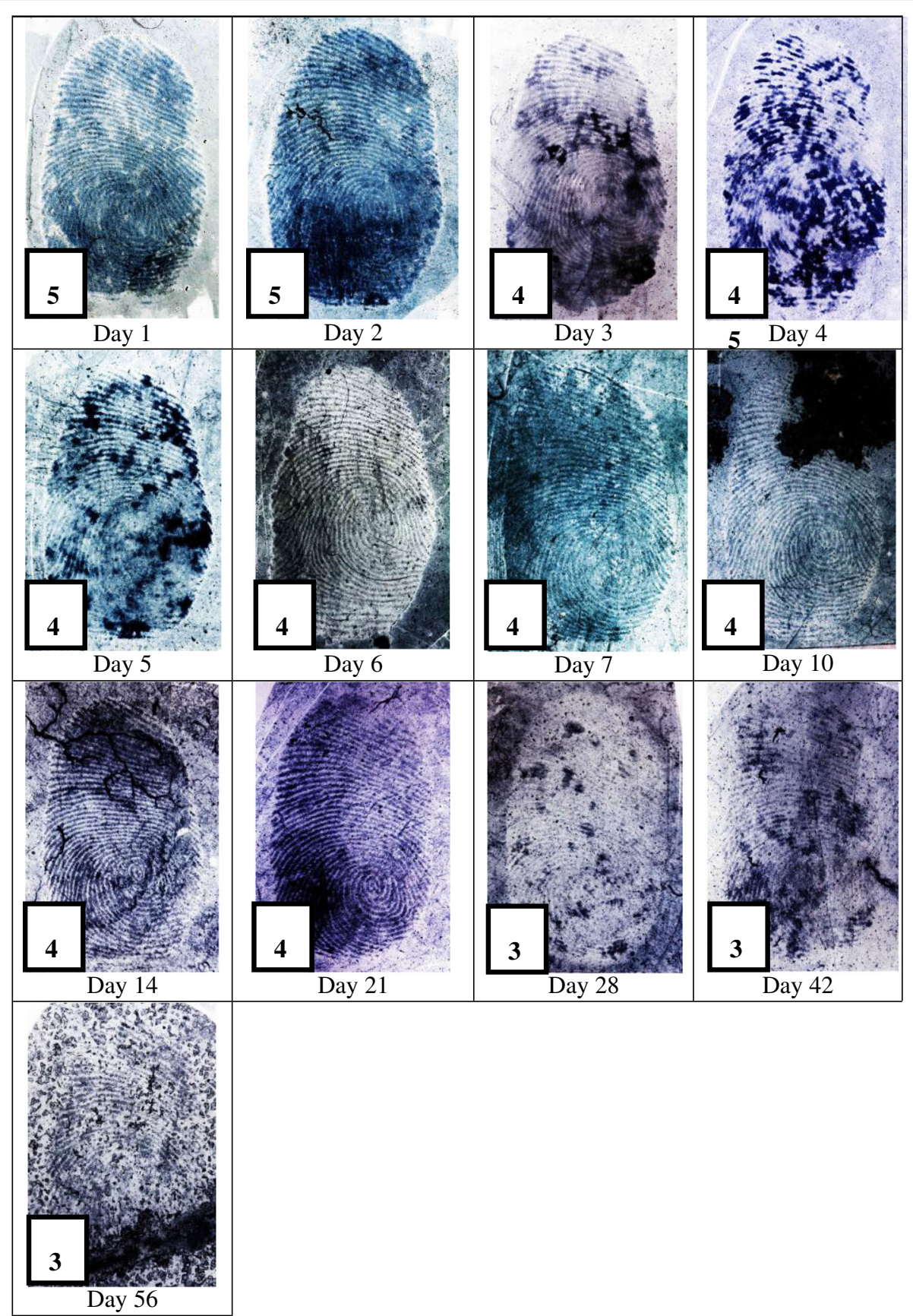

Fig. 15 Fingermarks recovered from the "face up" surface of the metal plates from day 1 to day 56

In this experiment, second-level details can be discerned on the fingermarks developed using Sudan black on the "face up" surface of the metal plates. Fingermarks with sufficient characteristics of second-level details are acceptable for identification purposes of individuals in forensic cases using the Biometric Fingerprint Identification System (BIOFIS).

As observed in the preliminary experiment, interferences such as water speckles and soil deposits were also encountered on the developed fingermarks. During the excavation of the metal plates, water speckle was not observed on the "face up" surface of the metal plates where the latent fingermarks were initially deposited. Therefore, the formation of water speckles on developed fingermarks was minimal.

The fingermarks developed on the "face down" surface of the metal plates were of poor quality with significant loss of ridge details. This was due to the formation of 
water speckles on all developed fingermarks that may cause rapid degradation of fingermark compositions. The images of the developed fingermarks are shown in Fig. 16. Fingermarks can be developed up to the sixth week, and the quality started to decline steadily after 3 weeks of exposure to the burial environment. No fingermarks were detected in the eighth week of the burial period. The general ridge path of the fingermarks was noticeable within the first week of burial interval, but limited ridge details were observed. After thorough examinations, the overall quality of the developed fingermarks can only permit first-level detail. Figure 17 shows the overall quality of the developed fingermarks for both orientations using Sudan black in the main experiment.

The metal plates were thoroughly inspected for any remains of visible fingermarks after the first lifting was completed. Second lifting was carried out to recover any noticeable remaining secondary fingermarks without additional enhancement. The secondary or second lift fingermarks were observed on the metal plates buried in both orientations (face up and face down) on day 10 onwards. Interestingly, no secondary fingermarks were observed in the first 7 days of the experiment.

The images of the secondary fingermarks after the lifting appeared inverted; the ridges appeared in a light colour, and the furrows in dark blue. Subsequently, the images of the fingermarks were digitally enhanced using Adobe ${ }^{\circ}$ Photoshop $\mathrm{CC}^{\ominus}$ software. The digital images of the fingermarks were first converted into greyscale images and inverted to make the ridges appeared in dark colour and the furrows in white. Figures 18 and 19 depict the images of fingermarks from the second lifting before and after the digital enhancement. It is evident that positive identification was achievable for the developed fingermarks recovered up to 56 days in the burial environment.

The results from this study demonstrated that the survivability of the fingermarks was highly dependent on the time or duration exposed to the burial environment. The quality of the fingermarks deteriorated and degraded when exposed to longer burial duration. The quality of the recovered fingermarks had declined steadily after the burial period of 28 days. Furthermore, the

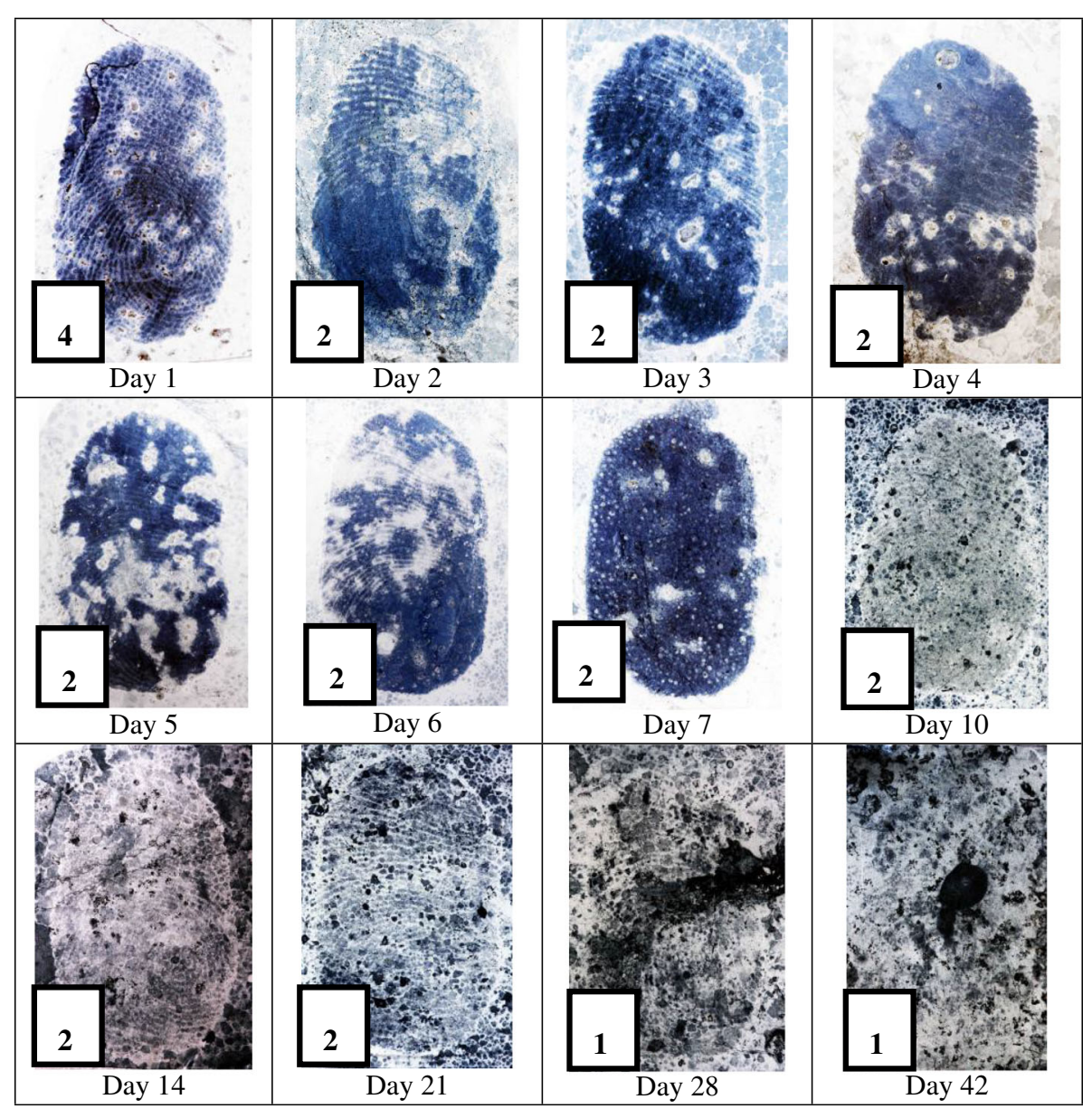

Fig. 16 Fingermarks recovered from the "face down" surface of the metal plates from day 1 to day 42 


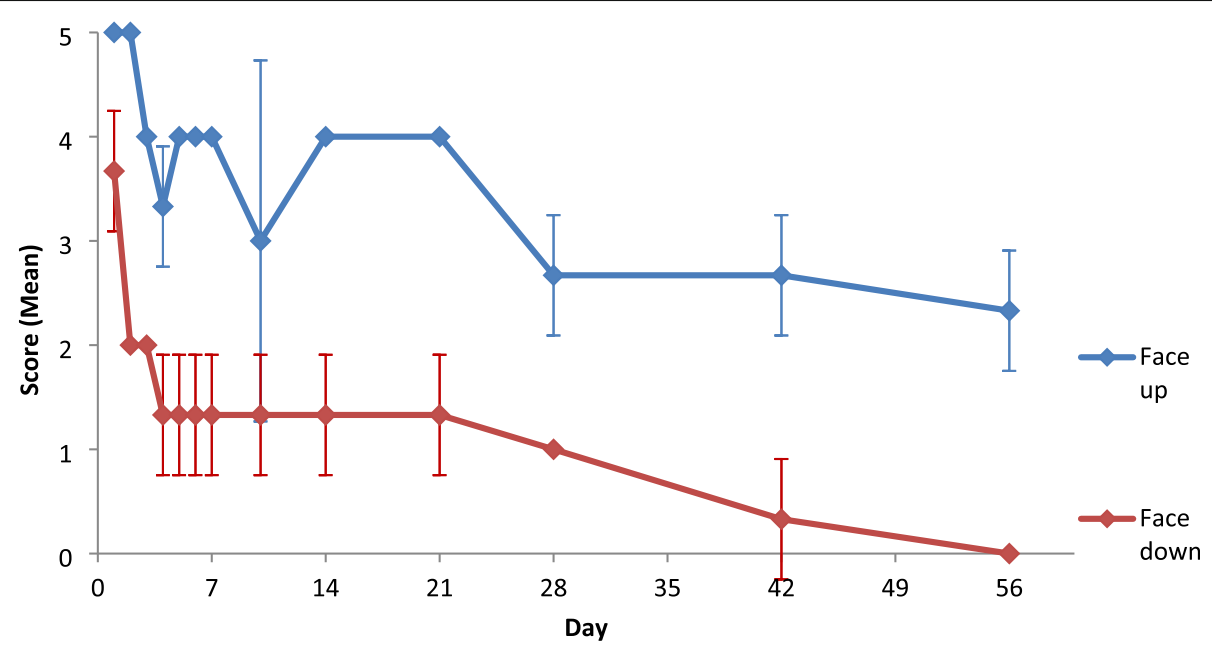

Fig. 17 The comparison of quality of recovered fingermarks in different orientations using Sudan black

longer the metal plates were exposed to the soil, the more soil adhered to the substrate surface (Cullen et al. 2010). The adhered soil was very difficult to be removed, and it may further damage the fingermarks during the cleaning and development or enhancement processes.

This study demonstrated that fingermarks were prone to the effect of the moisture in the soil. Excessive moisture had degraded the quality of the fingermarks recovered from burial environments. In a real forensic case, the recovery of buried evidence may take place after some time since the burial process. The burial location may have been exposed to rain before the evidence was recovered. Therefore, the detection of such fingermarks is a very challenging task for law enforcement agencies. By conducting the experiment directly in an outdoor burial setting, the soil may have a constant supply of natural moisture from the environment. Another way of conducting experiments by placing the soil in the container or box was proven to be difficult in controlling the moisture absorption and evaporation of the soil (Cullen et al. 2010). Moreover, the soil placed in the container may also lose its moisture consistently over time.

The moisture content of the soil at the burial location was $12.3 \%$. The moisture in the soil may not have a direct effect on the metal plates, but it may cause rapid degradation on the fingermark residue. The soil moisture can influence the breakdown and alter the process of biological samples in the burial environment (Carter et al. 2010). On the other hand, the different types of soil

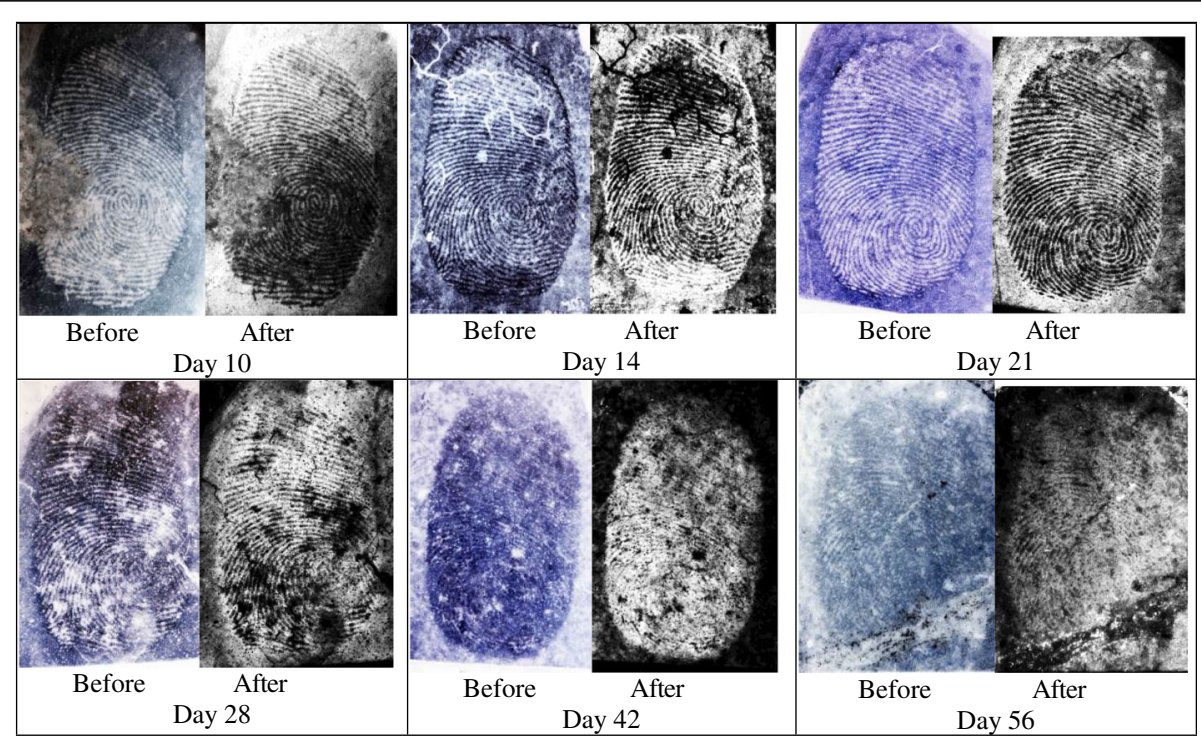

Fig. 18 Pre- and post-digital enhancement of "second lift" fingermarks on the "face up" surface of the metal plates 


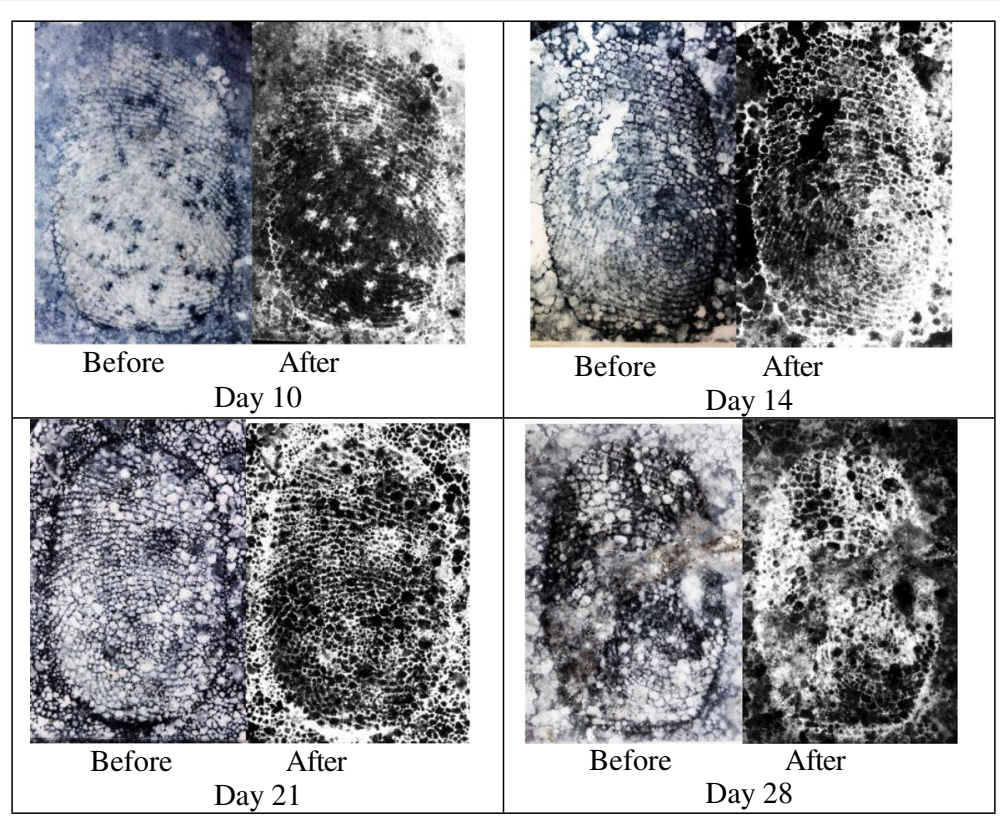

Fig. 19 Pre- and post-digital enhancement of "second lift" fingermarks underlying the "face down" of the metal plates

may have different effects on the degradation of buried biological samples. It is known that smaller soil particles have higher water retention capacity; therefore, the higher the clay composition, the higher the moisture in the soil. The moisture in the soil can affect the microbial activity in the soil, which has a significant influence on the decomposition process (Tumer et al. 2013).

The degradation of fingermarks in the burial environment may also be due to other parameters such as $\mathrm{pH}$ and temperature. The $\mathrm{pH}$ of sweat varies from 5 to 7.2 (Yamashita and French 2011). The soil in this study was acidic ( $\mathrm{pH}$ 5.4), which was still within the $\mathrm{pH}$ range of the sweat. The effects of soil $\mathrm{pH}$ on fingermark composition are unknown, but the previous study was conducted to determine the optimum $\mathrm{pH}$ for fingermark development methods in order to produce the best results (Gao et al. 2009).

The average daily surrounding temperature during the experiment was $31^{\circ} \mathrm{C}$ and $24^{\circ} \mathrm{C}$ for high and low temperatures, respectively. The temperature of the soil is lower than the surrounding air temperature at day and higher at night (Nuruddin and Tokiman 2005). It is believed that such temperature may not have a significant impact on the fingermarks as they were successfully developed in numerous studies after exposure to various temperatures (Dominick et al. 2011; Dhall et al. 2013; Gardner et al. 2016).

The metal plates bearing fingermarks were buried at the same depth $(10 \mathrm{~cm})$ in this study. Hence, the effect of different depths on fingermarks was not investigated in this study. It was suggested that the depth at which the specimens were buried was one of the factors that can affect the survival of bloody footwear impressions on various substrates buried in the soil (Cullen et al. 2010). However, fingermark composition may behave differently from a bloody footwear impression in the burial environment.

\section{Conclusion}

This study was carried out to investigate the persistence and ageing of latent fingermarks in the burial environment and to determine the most chemical to enhance such fingermarks. This experiment demonstrated that Sudan black was the most effective chemical to develop fingermarks buried in the soil, and hence, it was chosen for development in the main experiment. Small particle reagent and powder dusting produced acceptable results at an earlier stage and can be used as an alternative for developing freshly buried fingermarks on the metal plates. Oil red $\mathrm{O}$ and crystal violet, on the other hand, yielded poor quality fingermarks throughout the experiment.

The main experiment was carried out in an outdoor burial setting to mimic the real casework. This study concluded that latent fingermarks exposed to the burial environment can still be developed if appropriate chemical enhancement was used. The latent fingermarks of good quality were still recovered using Sudan black after being buried in the soil for up to 8 weeks. The position of the substrates, when buried, also had an impact on the development results. Fingermarks buried in the "face up" position had better quality and more ridge details as compared to those buried in the "face down" position. 
The latter sustained more interferences due to the accumulation of moisture on the surface of the substrate, which has greatly degraded the quality of the recovered fingermarks. Secondary fingermarks were also observed in this study, and the second lifting was attempted to recover them. It was evident that secondary fingermarks, when lifted, have still been useful for identification and must also be considered when developing fingermarks on buried items in forensic cases.

\section{Abbreviations}

BIOFIS: Biometric Fingerprint Identification System; DNA: Deoxyribonucleic acid; SPR: Small particle reagent

\section{Acknowledgements}

Not applicable.

\section{Authors' contributions}

All authors contributed to the design of the study. Yam Tze Yong performed the experiments. All authors analysed the data and discussed and wrote the manuscript. The authors read and approved the final manuscript.

\section{Authors' information}

Not applicable.

\section{Funding}

Financial support for this research is from the Universiti Sains Malaysia (USM) Research University Grant: 1001/PPSK812125.

\section{Availability of data and materials}

Please contact the authors for data requests.

\section{Ethics approval and consent to participate}

Informed consent has been obtained from the participating individual.

\section{Competing interests}

The authors declare that they have no competing interests.

\section{Author details}

${ }^{1}$ Royal Malaysia Police Forensic Laboratory, Cheras, Selangor, Malaysia. ${ }^{2}$ Forensic Science Programme, School of Health Sciences, Universiti Sains Malaysia, Kubang Kerian, Kota Bharu, Kelantan, Malaysia. ${ }^{3}$ Biomedicine Programme, School of Health Sciences, Universiti Sains Malaysia, Kubang Kerian, Kota Bharu, Kelantan, Malaysia.

Received: 14 November 2019 Accepted: 27 September 2020

Published online: 02 October 2020

\section{References}

Archer NE, Charles Y, Elliot JA, Jickells S (2005) Changes in the lipid composition of latent fingerprint residue with time after deposition on a surface. Forensic Sci Int 154(2-3):224-239

Azman AR, Mahat NA, Abdul Wahab R, Abdul Razak Fl, Hamzah HH (2018) Novel safranin-tinted Candida rugosa lipase nanoconjugates reagent for visualizing latent fingerprints on stainless steel knives immersed in a natural outdoor pond. Int J Mol Sci 19(6):1576

Beaudoin A (2004) New technique for revealing latent fingerprints on wet, porous surface: oil red O. J Forensic Ident 54(4):413-421

Bossers LCAM, Roux C, Bell M, McDonagh AM (2011) Methods for the enhancement of fingermarks in blood. Forensic Sci Int 210:1-11

Cadd S, Islam M, Manson P, Bleay S (2015) Fingerprint composition and aging: a literature review. Sci Justice 55:219-238

Carter DO, Yellowless D, Tibbett M (2010) Moisture can be the dominant environmental parameter governing cadaver decomposition in soil. Forensic Sci Int 200:60-66

Champod C, Kennard CJ, Margot P, Stoilovic M (2004) Fingerprints and other ridge skin impressions. CRC Press, Boca Raton
Cullen S, Otto A, Cheetham PN (2010) Chemical enhancement of bloody footwear impressions from buried substrates. J Forensic Identification 60(1): $45-83$

Dewes L, Goonetilleke A, Cox M (2006) Assessment of physical and chemical properties of sub-tropical soil to predict long term effluent treatment potential. Soil Sediment Contam 14(3):211-230

Dhall JK, Sodhi GS, Kapoor AK (2013) A novel method for the development of latent fingerprints recovered from arson simulation. Egypt J Forensic Sci 3: 99-103

Dominick AJ, Daeid NN, Bleay SM (2011) The recoverability of fingerprints on nonporous surfaces exposed to elevated temperatures. J Forensic Identification 61(5):520-536

Friesen JB (2015) Forensic chemistry: The revelation of latent fingerprints. J Chem Educ 92:497-504

Gao D, Li F, Song J, Xu X, Zhang Q, Niu L (2009) One step to detect the latent fingermarks with gold nanoparticles. Talanta 80:479-483

Gardner SJ, Cordingley TH, Francis SC (2016) An investigation into effective methodologies for latent fingerprint enhancement on items recovered from fire. Sci Justice:241-246

Home Office CAST (2017) Fingerprint source book. Home Office, London International Fingerprint Research Group (IFRG) (2014) Guidelines for the assessment of fingermark detection techniques. J Forensic Ident 64:174-200

Jasuja OP, Kumar P, Singh G (2015) Development of latent fingermarks on surfaces submerged in water: optimization studies for phase transfer catalyst (PTC) based reagent. Sci Justice 55:335-342

Jasuja OP, Singh G, Sodhi GS (2007) Development of latent fingerprints on the sticky side of adhesive tapes: phase transfer catalyst-based formulation. J Can Soc Forensic Sci 40(1):1-13

Kelly ME (2019) Introduction to forensic chemistry. CRC Press, Boca Raton

Nizam F, Knaap W, Stewart JD (2012) Development of fingerprints using electrolysis: a technical report into the development of fingerprints on fired brass cartridge cases. J Forensic Identification 62(2):129-142

Nuruddin AA, Tokiman L (2005) Air and soil temperature characteristics of two sizes forest gap in tropical forest. Asian J Plant Sci 4(2):144-148

Praska N, Langenburg G (2013) Reactions of latent prints exposed to blood. Forensic Sci Int 224:51-58

Rohatgi R, Kapoor AK (2016) Development of latent fingerprints on wet nonporous surfaces with SPR based on basic fuchsin dye. Egypt J Forensic Sci: 179-184

Sodhi GS, Kaur J (2012) A novel fluorescent small particle reagent for detecting latent fingerprints on wet non-porous items. Egypt J Forensic Sci 2:45-47

Trapecar M (2012a) ${ }^{a}$ Finger marks on glass and metal surfaces recovered from stagnant water. Egypt J Forensic Sci 2:48-53

Trapecar M (2012b) ${ }^{\text {b }}$ Fingerprint recovery from wet transparent foil. Egypt J Forensic Sci 2:126-130

Tumer AR, Karacaoglu E, Namli A, Keten A, Farasat S, Akcan R, Sert O, Odabasi AB (2013) Effects of different types of soil on decomposition: an experimental study. Legal Med 15:149-156

Voss-De Haan P (2006) Physics and fingerprints. Contemp Phys 47(4):209-230

Yamashita B, French M (2011) Chapter 7: Latent print development. In: Bleay S, Cantu AA, Inlow V, Ramotowski RS, Sears VG, Wakefield M (eds) The Fingerprint Sourcebook. National Institute of Justice, pp 1-67

\section{Publisher's Note}

Springer Nature remains neutral with regard to jurisdictional claims in published maps and institutional affiliations. 